\title{
Article
}

\section{D Printing of Macro Porous Sol-Gel Derived Bioactive Glass Scaffolds and Assessment of Biological Response}

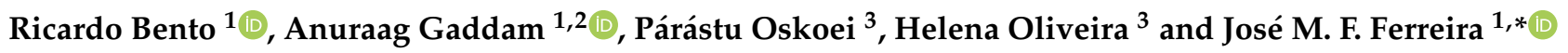 \\ 1 CICECO-Aveiro Institute of Materials, Department of Materials and Ceramic Engineering, \\ University of Aveiro, Santiago University Campus, 3810-193 Aveiro, Portugal; ricardobento@ua.pt (R.B.); \\ anuraagg@ua.pt (A.G.) \\ 2 Instituto de Física de São Carlos, Universidade de São Paulo, São Carlos 13566-590, SP, Brazil \\ 3 Department of Biology \& CESAM, University of Aveiro, Santiago University Campus, \\ 3810-193 Aveiro, Portugal; parastu.oskoei@ua.pt (P.O.); holiveira@ua.pt (H.O.) \\ * Correspondence: jmf@ua.pt; Tel.: +351-234-370-242
}

Citation: Bento, R.; Gaddam, A.; Oskoei, P.; Oliveira, H.; Ferreira, J.M.F. 3D Printing of Macro Porous Sol-Gel Derived Bioactive Glass Scaffolds and Assessment of Biological Response. Materials 2021, 14, 5946. https:// doi.org/10.3390/ma14205946

Academic Editor: Serena Esposito

Received: 14 August 2021

Accepted: 6 October 2021

Published: 10 October 2021

Publisher's Note: MDPI stays neutral with regard to jurisdictional claims in published maps and institutional affiliations.

Copyright: (c) 2021 by the authors. Licensee MDPI, Basel, Switzerland. This article is an open access article distributed under the terms and conditions of the Creative Commons Attribution (CC BY) license (https:// creativecommons.org/licenses/by/ $4.0 /)$.

\begin{abstract}
D printing emerged as a potential game-changer in the field of biomedical engineering. Robocasting in particular has shown excellent capability to produce custom-sized porous scaffolds from pastes with suitable viscoelastic properties. The materials and respective processing methods developed so far still need further improvements in order to obtain completely satisfactory scaffolds capable of providing both the biological and mechanical properties required for successful and comprehensive bone tissue regeneration. This work reports on the sol-gel synthesis of an alkali-free bioactive glass and on its characterization and processing ability towards the fabrication of porous scaffolds by robocasting. A two-fold increase in milling efficiency was achieved by suitably adjusting the milling procedures. The heat treatment temperature exerted a profound effect on the surface area of mesoporous powders. Robocasting inks containing 35 vol.\% solids were prepared, and their flow properties were characterized by rheological tests. A script capable of preparing customizable CAD scaffold geometries was developed. The printing process was adjusted to increase the technique's resolution. The mechanical properties of the scaffolds were assessed through compressive strength tests. The biomineralization ability and the biological performance were assessed by immersing the samples in simulated body fluid (SBF) and through MTT assays, respectively. The overall results demonstrated that scaffolds with macro porous features suitable for bone ingrowth (pore sizes of $\sim 340 \mu \mathrm{m}$ after sintering, and a porosity fraction of $\sim 70 \%$ ) in non-load-bearing applications could be successfully fabricated by 3D printing from the bioactive glass inks. Moreover, the scaffolds exhibited good biomineralization activity and good biocompatibility with human keratinocytes, suggesting they are safe and thus suited for the intended biomedical applications.
\end{abstract}

Keywords: bioactive glasses; alkali-free; sol-gel; bone regeneration; tissue engineering

\section{Introduction}

For years, subtractive manufacturing, consisting of removing, treating, and shaping a feed material into a product with desired properties and shapes, has been the paradigm in manufacturing and industrial processes. However, in the recent past, technological developments in the manufacturing and digital fields have led to the candidacy of additive manufacturing (AM) as a potential gateway into a new industrial revolution [1]. AM is now, more than ever, the target of numerous research efforts in multiple fields to assess its potential, limitations, and feasibility [2,3]. Its impact is not merely on the industrial sector [2-7] but also economics [4,8-11], fiscal policy, and social welfare [9] as the manufacturing capability of various products suddenly becomes possible in the household. Perhaps the biggest impact of AM is its ability to create intricate and easily customizable geometries not feasible through traditional methods, which is particularly useful when coupled with finite element method (FEM) analysis to produce more efficient parts, to model unique 
designs for expositions, or to produce extremely precise implants that can be custom-fitted into patients, opening up a whole new paradigm in biomedical engineering, although the regulation and success rate of these custom devices presents a possible legal nightmare [1].

Robocasting is a 3D printing technique that uses a triaxial (XYZ) dispenser to extrude a polymeric, metallic, or ceramic slurry in a layer-by-layer fashion, and the extruded filament fuses with the existing layers. This simple technique relies mostly on the viscoelastic properties of the pastes, which impose design limitations since arching or overhanging features as well as hollow segments are impossible to reproduce without the use of supporting or sacrificial materials. This simplicity allows, however, great flexibility in the choice of printing materials [12]. Ceramic slurries, also called inks, are traditionally composed of ceramic powders-typically with particle size distributions and average sizes ranging from submicrometric to several microns of diameter-dispersed in a liquid (such as water) with the aid of minimal amounts of selected dispersants, binders, and coagulating agents [13]. The reliance on the viscoelastic properties of the printing inks puts the rheology and viscosity of the paste in a central position. Robocasting pastes should be homogeneous so as to avoid any change of pressure in the syringe and uneven densities in the green body. Cesarano et al. [14] established three criteria that a ceramic ink should follow: (i) the viscosity should allow it to flow through a small orifice when submitted to modest shear rates; (ii) the ink must stop flowing after being deposited onto the substrate and, therefore, exhibit a fast recovery of the internal structure; (iii) the deposited filaments must be capable of supporting the upper layers without yielding [13]. For this, the ideal paste should be shear-thinning (pseudoplastic) when flowing and shear-thickening (dilatant) upon deposition.

The printing pastes should have high solids loadings to prevent the formation of cracks upon the drying and sintering processes [15]. To achieve such demanding flow properties, different approaches have been employed. Depending on the specifications of the solid and liquid components involved in the paste formulation, namely on the solidliquid interactions and the packing ability of the powder, the starting suspensions can be prepared with a high solids loading (over 50 vol.\%) in water with a very minute quantity of processing additives. The common approach is searching for a trade-off between a high solids loading and a relatively low viscosity-usually the use of dispersant concentrations just below the pseudo-plastic to dilatant transition - to enable the achievement of a high degree of homogeneity. However, such suspensions are not suitable for printing as the individual particles are prone to undergo size segregation under shear, which may clog the extrusion nozzles. The dispersing agents alone can hardly enable us to adjust and control the rheological properties of suitable printing pastes. Accordingly, other processing additives need to be added in order to cause drastic changes on the rheological properties, transforming a fluid suspension into an extrudable paste. With this purpose, thickening agents are usually employed to increase the viscosity of the dispersing liquid to hinder particle segregation under shear. They also act as binders, enhancing the mechanical properties of the green parts [14]. Furthermore, the addition of a coagulating agent having an anionic character opposite to that of the dispersant is commonly required to increase the stiffness of the ink and to confer it the above referred viscoelastic properties required for printing [15]. Therefore, the required rheological characteristics for printing rely on the overall complex interactions taking place within the pasty-like system, which also affect the following processing steps, such as drying and sintering [15]. Different strategies were attempted to improve the printability of different materials by robocasting. High solids loading pastes were developed using anionic polyelectrolytes as dispersants to electro-sterically stabilize the starting suspensions and provide good homogenization, cellulose-based binders, and a cationic polyethylenimine (PEI) as a coagulation agent [15-19]. Recently, the use of hydrogels, most notably Pluronic F127, has been given attention in the processing of difficult-to-disperse powders as an alternative approach to obtaining the highly printable pastes prepared thereof since the interactions among the imbuing particles lose relevance and, therefore, any powdered material is theoretically mixable [20,21]. Besides, Pluronic 
F127-based pastes are highly stable and can be stored over long durations, which, coupled with their ease of preparation, could facilitate the production of such pastes for commercial purposes [12,22]. Previous studies on the biological properties assessment of sol-gel derived bioactive glasses are scarce. A four-component, high-silica sol-gel glass with a molar composition of $67 \mathrm{SiO}_{2}-24 \mathrm{CaO}-2.5 \mathrm{Na}_{2} \mathrm{O}-2 \mathrm{P}_{2} \mathrm{O}_{5}$ containing small amounts of $\mathrm{CuO}$ and $\mathrm{La}_{2} \mathrm{O}_{3}$ revealed that co-doping with $\mathrm{Cu}^{2+}$ and $\mathrm{La}^{3+}$ could benefit the viability of $\mathrm{C} 13895$ lymphoblast cells [23]. So far, no biocompatibility studies have been carried out and reported for the better-balanced bioactive glass composition disclosed here, justifying the pertinence of evaluating its biological performance.

\section{Materials and Methods}

\subsection{Bioactive Glass Synthesis}

A quaternary bioactive glass with composition $60 \mathrm{SiO}_{2}-34 \mathrm{CaO}-4 \mathrm{MgO}-2 \mathrm{P}_{2} \mathrm{O}_{5}(\mathrm{~mol} \%)$ was synthesized by the sol-gel technique from the following reagents: tetraethylorthosilicate (TEOS, $\mathrm{Si}\left(\mathrm{O}_{2} \mathrm{H}_{5}\right)$, $\geq 98 \%$ ) supplied by Sigma-Aldrich)(Sintra, Portugal), trietylphosphate (TEP, $\mathrm{O}_{4} \mathrm{P}\left(\mathrm{C}_{2} \mathrm{H}_{5} \mathrm{O}\right)$, $\geq 98 \%$ ) supplied by MERCK-Schuchardt (Darmstadt, Germany), magnesium nitrate hexahydrate $\left[\mathrm{Mg}\left(\mathrm{NO}_{3}\right)_{2} \cdot 6 \mathrm{H}_{2} \mathrm{O}\right)$ supplied by Scharlau (Barcelona, Spain)], and calcium nitrate tetrahydrate $\left[\mathrm{Ca}\left(\mathrm{NO}_{3}\right)_{2} \cdot 4 \mathrm{H}_{2} \mathrm{O}\right)$ supplied by Panreac (Barcelona, Spain)] as precursors for $\mathrm{Si}, \mathrm{P}, \mathrm{Mg}$, and $\mathrm{Ca}$ oxides, respectively. Nitric acid $\left(\mathrm{HNO}_{3} \geq 65 \%\right)$ supplied by Labkem (Dublin, Ireland) was used for catalysts to promote the hydrolysis of network $\mathrm{Si}$ and P precursors. The preparation of the batches was planned to yield $0.2 \mathrm{~mol}$ of bioactive glass by mixing $1.46 \mathrm{~g}$ of TEP, $25.00 \mathrm{~g}$ of TEOS, $2.05 \mathrm{~g}$ of magnesium nitrate, and $16.06 \mathrm{~g}$ of calcium nitrate. Two separate aqueous solutions were initially prepared by adapting a procedure reported by Ben Arfa et al. [24]. The solution of the network modifiers was prepared by adding the required amounts of $\mathrm{Ca}\left(\mathrm{NO}_{3}\right)_{2} \cdot 4 \mathrm{H}_{2} \mathrm{O}$ and $\mathrm{Mg}\left(\mathrm{NO}_{3}\right)_{2} \cdot 6 \mathrm{H}_{2} \mathrm{O}$ to $20 \mathrm{~mL}$ of deionized water under magnetic stirring for $1 \mathrm{~h}$. The network precursors were also dissolved in $20 \mathrm{~mL}$ of deionized water acidified with two drops of concentrated nitric acid under magnetic stirring for $1 \mathrm{~h}$. Then, both solutions were mixed and magnetically stirred for further $1 \mathrm{~h}$ before pouring into Petri dishes, and stored in an oven for $24 \mathrm{~h}$ at $100{ }^{\circ} \mathrm{C}$ to promote a relatively rapid sol-gel transition. As obtained, the transparent gel was quickly crushed in small granulates with a spatula and then put again in the same oven for drying. The xerogel was first ground into a fine powder using an agate pestle and mortar and then calcined at $600{ }^{\circ} \mathrm{C}$. The structural features of powders of this bioactive glass calcined at different temperatures $\left(600^{\circ} \mathrm{C}, 700^{\circ} \mathrm{C}\right.$, and $\left.800^{\circ} \mathrm{C}\right)$ have already been disclosed elsewhere [25], and they reveal that it remains completely amorphous within this entire calcination and sintering temperature range $\left(600-800{ }^{\circ} \mathrm{C}\right)$. The biomineralization ability of the same powders immersed in simulated body fluid (SBF) was also reported in that manuscript. The readers are requested to consult this article for the related information.

\subsection{Milling Procedures}

Milling procedures were adapted from the guidelines provided by Ben Arfa et al. [26,27] using a planetary mill (Ceramic instruments, type S2-1000, Sassuolo-Italy), at 390 RPM. Ethanol or acetone were tested as liquids for wet milling at the bioactive glass-to-liquid weight ratio of 1:1 in a sintered alumina jar of $300 \mathrm{~cm}^{3}$ capacity using yttria-stabilized zirconia balls with a $10 \mathrm{~mm}$ diameter (Tosoh, Tokyo, Japan). A mass of $15 \mathrm{~g}$ of bioactive glass was milled at a time (Table 1).

Table 1. Effects of wet milling liquids on milling efficiency.

\begin{tabular}{cccccc}
\hline Bioactive Glass & $\begin{array}{c}\text { Wet Milling } \\
\text { Liquids }\end{array}$ & $\begin{array}{c}\text { Milling } \\
\text { Conditions }\end{array}$ & $\begin{array}{c}\text { Recovered } \\
\text { Powder }\end{array}$ & $\begin{array}{c}\text { Sieve } \\
\text { Mesh }\end{array}$ & Powder Fraction $>63 \mu \mathrm{m}$ \\
\hline \multirow{2}{*}{$15 \mathrm{~g}$} & 15 g ethanol & \multirow{2}{*}{ h $390 \mathrm{RPM}$} & $12.88 \mathrm{~g}(86 \%)$ & $63 \mu \mathrm{m}$ & $6.14 \mathrm{~g}(\sim 47 \%)$ \\
& $15 \mathrm{~g}$ acetone & $13.35 \mathrm{~g}(89 \%)$ & $6.88 \mathrm{~g}(\sim 97 \%)$ \\
\hline
\end{tabular}




\subsection{Particle Characterization}

The particle size and its distribution were measured by laser diffraction using a particle size analyser (Coulter LS particle size analyser, Beckman Coulter, Mississauga, ON, Canada) with triplicate measurements. Average powder density was determined using triplicate measurements performed with a helium AccuPyc 1330 Pycnometer (Micromeritics Instrument Corporation, Norcross, GA, USA).

\subsection{Paste Formulations}

Hydrogels containing 33 wt.\% Pluronic F-127 in deionized water were chosen as processing media for the preparation of the robocasting inks. Two different volumes were prepared at a time: $5 \mathrm{~mL}$ and $10 \mathrm{~mL}$ stock solutions. Zirconia balls were added to both solutions to aid in the mixing process: 3 balls with a $5 \mathrm{~mm}$ diameter to the $5 \mathrm{~mL}$ stock, 6 balls with $5 \mathrm{~mm}$, and an additional 3 balls with $10 \mathrm{~mm}$ diameter to the $10 \mathrm{~mL}$ stock solution. Pastes were produced by adding the powders to the Pluronic F-127 hydrogels and mixing in a planetary centrifugal mixer (ARE-250, Thinky Corp., Tokyo, Japan) at different RPM, resulting in homogenized inks.

\subsection{Rheological Characterization of the Inks}

Rheological measurements of the inks were taken using a Kinexus Pro+ Rheometer (Malvern Instruments, Westborough, MA, USA). A cone-plate geometry $\left(4^{\circ} / 40 \mathrm{~mm}\right)$ with a gap of $150 \mu \mathrm{m}$ was adopted to test their flow behaviours under the rotational mode. Their viscoelastic properties were assessed using parallel plates with a gap of $1 \mathrm{~mm}$ under oscillatory mode at the frequency of $1 \mathrm{~Hz}$.

\subsection{Printing Parameters}

A robocasting printer (3-D Inks, Stillwater, Littleton, CO, USA) on a 4-axis setup (XYZU) was used to print the scaffolds. The piston mechanism was custom built. The paste was loaded onto syringes (Luer locker, $3 \mathrm{~mL}$, Nordson, Westlake, OH, USA) coupled with extruding nozzles (Optimum general purpose dispense-tips, internal diameter $410 \mu \mathrm{m}$, Nordson, Westlake, OH, USA). Printing atmosphere was controlled using an air humidifier (SHF 911GR, Sencor, Ricany Czech Republic) and air conditioning, resulting in relatively constant printing temperatures of $25^{\circ} \mathrm{C}$ and an average humidity of $80 \%$. Printed specimens were layered on a $100 \times 100 \times 1 \mathrm{~mm}$ alumina plaque with a thin layer of anti-sticking agent (Zhengzhou Keija Furnace CO., LTD, Zhengzhou, China) at a printing speed of $10 \mathrm{~mm} / \mathrm{s}$.

Proprietary RoboCAD software (3-D Inks, Stillwater, OK, USA) was used in freeform $\mathrm{CAD}$ modelling to produce square scaffolds. Specimens were left for 1 day at $38^{\circ} \mathrm{C}$ to allow even and slow drying before being stored at $100{ }^{\circ} \mathrm{C}$ in an oven.

\subsection{Debinding, Sintering, and Morphological Observation of the Scaffolds}

Thermogravimetric analysis (TGA) was employed to determine the parameters for debinding and sintering using a Netzsch STA 449F1 calorimeter. Dilatometry measurements (Bahr Thermo Analyzer DIL 801L, Hillhorst, Germany) under a heating rate of $10^{\circ} \mathrm{C} \mathrm{min}-1$ were carried out using rectangular samples with $11 \mathrm{~mm} \times 4 \mathrm{~mm} \times 2 \mathrm{~mm}$ prepared by robocasting. Thereafter, the bioactive glass scaffolds were debinded at $400^{\circ} \mathrm{C}$ for $4 \mathrm{~h}$ with a heating rate of $0.5^{\circ} \mathrm{C} \mathrm{min}^{-1}$, followed by sintering at $600,700,800$, and $900{ }^{\circ} \mathrm{C}$ for $4 \mathrm{~h}$ with a heating rate of $0.5^{\circ} \mathrm{C} \mathrm{min}-1$. For the morphological observation, the scaffolds were covered with a thin $(15 \mathrm{~nm})$ carbon layer using a thin film deposition system (PVD 75, Kurt J. Lesker Co., Jefferson Hills, PA, USA) before being examined using a Hitachi S4100 Scanning Electron Microscope with a $15.0 \mathrm{kV}$ accelerating voltage.

\subsection{Assessment of the Mechanical Properties through Compressive Strength Tests}

The compressive strength of the scaffolds was determined under uniaxial testing with 5 samples using a universal testing machine (AG-IS10kN, Shimadzu, Kyoto, Japan) at a 
constant speed of $0.5 \mathrm{~mm} / \mathrm{min}$ in the perpendicular direction to the printing plane with a $5 \mathrm{kN}$ cell.

\subsection{Assessment of the Biological Properties through In Vitro Cytotoxicity Assays}

The cytotoxicity of the bioactive glass scaffolds was assessed using the human osteoblastlike cell line MG-63, kindly provided by INEB, University of Porto (Porto, Portugal. Cells were cultured in Dulbecco's modified Eagle's Medium (DMEM), supplemented with $10 \%$ fetal bovine serum (FBS), $2 \mathrm{mM}$ L-glutamine, $1 \times 10^{4} \mathrm{U} / \mathrm{mL}$ penicillin/streptomycin, and $250 \mu \mathrm{g} / \mathrm{mL}$ fungizone (all medium components from Life Technologies, Carlsbad, $\mathrm{CA}, \mathrm{USA}$ ) at $37{ }^{\circ} \mathrm{C}$ in a $5 \% \mathrm{CO}_{2}$ humidified atmosphere. Extracts from the different scaffolds were prepared by placing a scaffold in $10 \mathrm{~mL}$ DMEM culture medium, followed by incubation at $37{ }^{\circ} \mathrm{C}$ in a $5 \% \mathrm{CO}_{2}$ humidified atmosphere for $24 \mathrm{~h}$. Cytotoxicity of the extracts was assessed by the colorimetric MTT assay [28]. Cells were seeded in a 96-well plate at $1 \times 10^{3}$ cells per well, and, after cell adhesion, the culture medium was replaced by the different scaffold extracts at $100 \%$ concentration or diluted to 50\% with fresh DMEM medium. MG-63 cells exposed to DMEM medium were used as negative control. Cells were further incubated for $24 \mathrm{~h}$ at the same temperature and atmosphere conditions as before. After incubation, $50 \mu \mathrm{L}$ of an MTT (Sigma-Aldrich, St. Louis, MO, USA) solution (1 mg/mL in PBS pH 7.2), a yellow tetrazolium dye, were added to each well followed by further incubation for $4 \mathrm{~h}$. Living cells reduce the MTT to purple formazan crystals. Then, the culture medium with MTT was removed and replaced by $150 \mu \mathrm{L}$ of dimethyl sulfoxide (DMSO) and placed in a shaker for $2 \mathrm{~h}$ to dissolve the formazan crystals. Absorbance measurements were used to calculate cell viability according to Equation:

$$
\text { Cell Viability }(\%)=\left(\frac{\text { AbsSample }- \text { AbsDMSO }}{\text { AbsControl }- \text { AbsDMSO }}\right) \times 100
$$

The absorbance of the samples was measured with a BioTeK Synergy HT plate reader (Synergy HT Multi-Mode, BioTeK, Winooski, VT, USA) at $570 \mathrm{~nm}$ with blank corrections.

\section{Results and Discussion}

\subsection{Sol-Gel Synthesis}

Homogeneous and transparent solutions were obtained from all the precursors using deionized water as a single solvent, as described in our work [25]. The dissolution of the Si and P network precursors was facilitated by the addition of two drops of concentrated nitric acid $\left(\mathrm{HNO}_{3} \geq 65 \%\right)$, which also acted as catalysts to promote their hydrolysis. The solution of the network modifiers soon became transparent due to their high solubility. The solution of the network formers became transparent in less than 20 min of magnetic stirring. The mixing of both separately prepared solutions resulted in a homogeneous transparent solution, which was kept under magnetic stirring for another hour. After being poured into Petri dishes and moved to an oven at $100{ }^{\circ} \mathrm{C}$, this overall solution underwent a relatively rapid sol-gel transition, which is useful to prevent the chemical segregation of the components, generating a transparent gel. The preliminary crushing of the fresh gel proved to be very helpful, facilitating the subsequent further grinding of the xerogel.

\subsection{Milling Procedures}

The milling of the bioactive glass powder that was calcined at $600{ }^{\circ} \mathrm{C}$ was performed by first crushing it with an agate pestle and mortar until the particles could pass through a $150 \mu \mathrm{m}$ sieve. These particles were then further milled in ethanol with a weight ratio of 1:1 using $10 \mathrm{~mm}$ diameter zirconia balls at a fixed weight ratio of 1:10, as described above and elsewhere [26,27]. After $1 \mathrm{~h}$ of milling, the effective removal of all the liquid and powder from the jar to a Petri dish for the subsequent drying step was difficult. To overcome this inconvenience, acetone was tested as an alternative milling liquid at the same 1:1 weight ratio. After $1 \mathrm{~h}$ of milling in acetone, the powder could be easily removed from the jar and immediately brushed against a $63 \mu \mathrm{m}$ sieve, circumventing the need for the drying 
step. This procedure was simpler, more time-effective, and presented higher efficiency and material recovery, as seen in Table 1 . The average density of the milled bioactive glass powder is reported in Table 2.

Table 2. Average density of the bioactive glass calcined at $600{ }^{\circ} \mathrm{C}$.

\begin{tabular}{ccc}
\hline Weight $(\mathrm{g})$ & Average Volume $\left(\mathrm{cm}^{\mathbf{3}}\right)$ & Density $\mathbf{( g / \mathrm { cm } ^ { 3 } )}$ \\
\hline 1.59 & 0.595 & $2.672 \pm 0.010$ \\
\hline
\end{tabular}

The particle size distribution of the milled powder determined by laser scattering is present in Figure 1. A relatively broad distribution within the range of 0.2 to $20 \mu \mathrm{m}$ can be observed with a slight right skewness and a mean particle size of $4.63 \pm 3.58 \mu \mathrm{m}$.

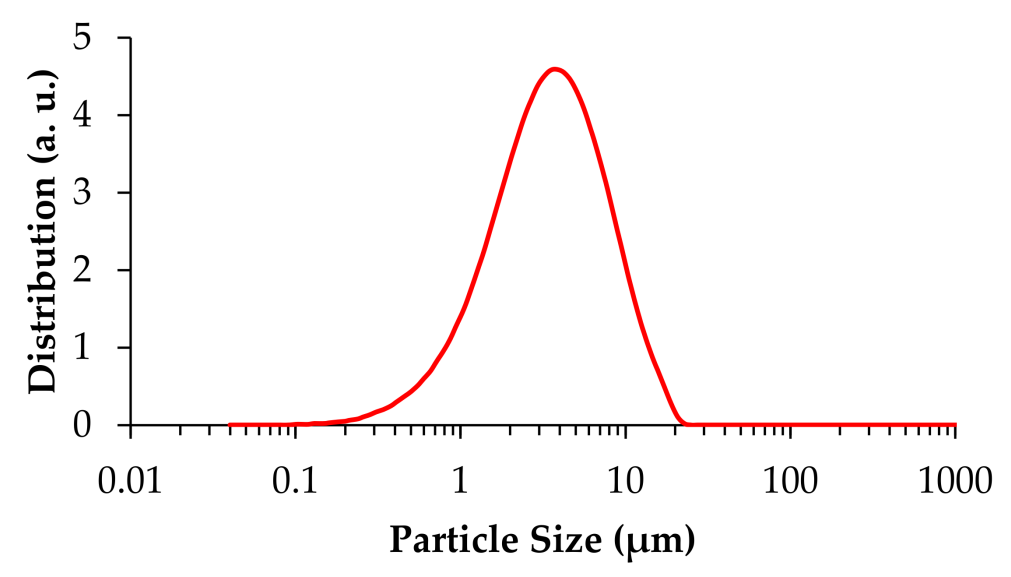

Figure 1. The particle size distribution of the milled powder.

\subsection{Paste Preparation}

Pluronic F-127 hydrogels provide a more rapid and simpler way of producing pastes for robocasting, circumventing the need to test out multiple concentrations of processing additives. On the other hand, their relatively high viscosities limit the maximum achievable solids loading, which harms the capacity to produce dense, monolithic pieces. However, as this study focuses on the production of porous scaffolds for tissue regeneration, this compromise was taken. In this work, six different solids loadings were initially attempted: $10,20,25,30,35$, and $40 \mathrm{vol} . \%$ to understand their effects on the flow properties of the pastes. At $40 \mathrm{vol} . \%$, the viscosity was too high, hindering the preparation of a properly mixed and homogeneous ink.

The pastes were mixed by first storing the Pluronic F-127 hydrogel in a freezer until it became more fluid. Then, all the powder was added and mixed at once at high rotations (1400-1600 RPM) for $2 \mathrm{~min}$, resulting in homogenous pastes.

\subsection{Rheological Properties of the Inks}

The printing ability of the pastes was assessed through rheological tests. Figure 2 displays the apparent viscosity versus shear rate curves of the pastes containing solids loadings varying from 10 to $35 \mathrm{vol} \%$. An expected gradual increase in the viscosity with increasing additions of solid particles is observed within the shear rate range from about 0.3 to $100 \mathrm{~s}^{-1}$, especially within the interval from 0.3 to $10 \mathrm{~s}^{-1}$. Furthermore, all the plotted curves exhibit almost linear variations of viscosity with increasing shear rates. This shearthinning behavior is an important requisite for $3 \mathrm{D}$ printing. The curves tend to overlap under near zero shear viscosity conditions (shear rates $<0.3 \mathrm{~s}^{-1}$ ), reflecting the intrinsic interactions between the hydrophobic and hydrophilic segments of the Pluronic F-127 chains in the hydrogel under rest conditions. For the deformation to start, the polymeric network needs to undergo a certain structural remodelling to enable the polymeric chains 
to gradually align along the flow direction, which is likely to require an extra applied stress (yield stress). This is reflected in the slight increase in the apparent viscosity observed for very low shear rates before it drops due to shear-thinning. Moreover, the flow curves of the pastes containing 20, 25, and 30 vol.\% solids tend to almost overlap within the interval from about 10 to $100 \mathrm{~s}^{-1}$, meaning that their rheological properties under these conditions are mostly dictated by the intrinsic interactions between the hydrophobic and hydrophilic segments of the Pluronic F-127 chains. However, with a further increase in the solids loading to $35 \mathrm{vol} \%$, the system becomes more crowded with bioactive glass particles, which disturb the polymeric chain interactions while contributing more decisively to the stiffening of the paste, explaining the jump observed in the respective curve in Figure 2.

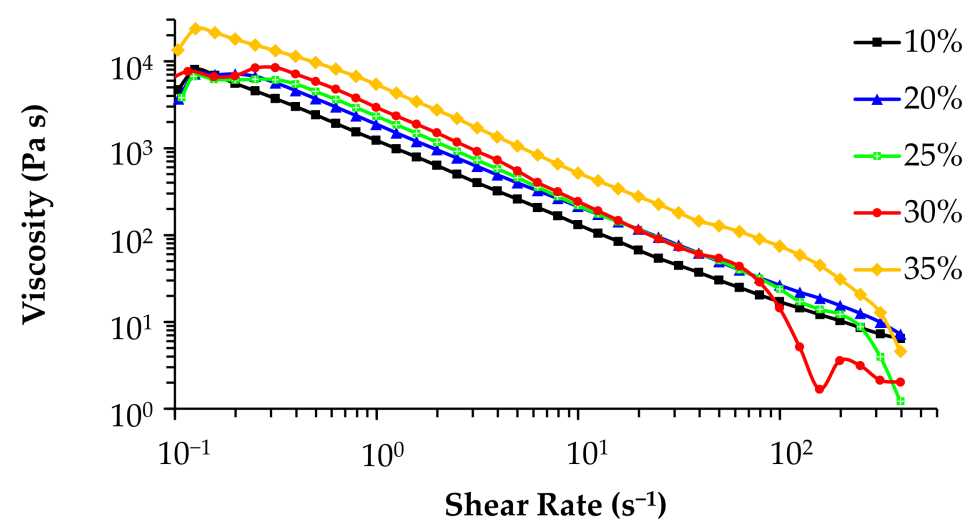

Figure 2. Dependence of the flow properties (viscosity vs. shear rate curves) on solid concentration.

The pastes were also tested in oscillatory mode. The lower solids loadings ( $<30$ vol.\%) did not confer sufficient stiffnesses to the inks to enable good shape retention capability of the extruded filaments, as can be deduced from the corresponding viscoelastic parameters of the inks plotted in Figure 3. The elastic modulus $\left(G^{\prime}\right)$ significantly increases with increasing solid concentrations, reaching a plateau at about $10 \mathrm{kPa}$ at $20-25 \mathrm{vol} . \%$ and at about $30-40 \mathrm{kPa}$ at 30-35 vol.\%, which are below the satisfactory level. For good printing and shape retention capability, $\mathrm{G}^{\prime}$ values should be at least one order of magnitude higher than those that are usually required [29].

The different possible strategies for ink preparation must be carefully selected considering the surface chemistry of the materials to be processed [20,21,30,31]. For example, the standard approach, using an anionic dispersant and a cationic coagulant, such as PEI, proved to be completely useless for printing $45 S 5$ bioactive glass scaffolds [30,31]. This problem could be overcome by using long chain length $\left(250,000 \mathrm{~g} \mathrm{~mol}^{-1}\right)$, sodium carboxymethyl cellulose (CMC) as a single processing additive (dispersant, binder, and stiffening agent). The use of Pluronic F-127 hydrogels as a dispersion medium also offers this obvious advantage of simplifying the ink formulation from the processing additives viewpoint.

This option for Pluronic F-127 hydrogels is fully justified when the powder to be dispersed undergoes some ionic leaching that would promote early and undesirable coagulation phenomena and unstable inks [21], or when dealing with poor wetting powders, such as metallic $\mathrm{Al}$ [20]. On the other hand, when the powder undergoes hydrolysis and non-stoichiometric dissolution reactions, the standard approach of using dispersant and PEI can only be used for surface-treated powders against hydrolysis [32]. 

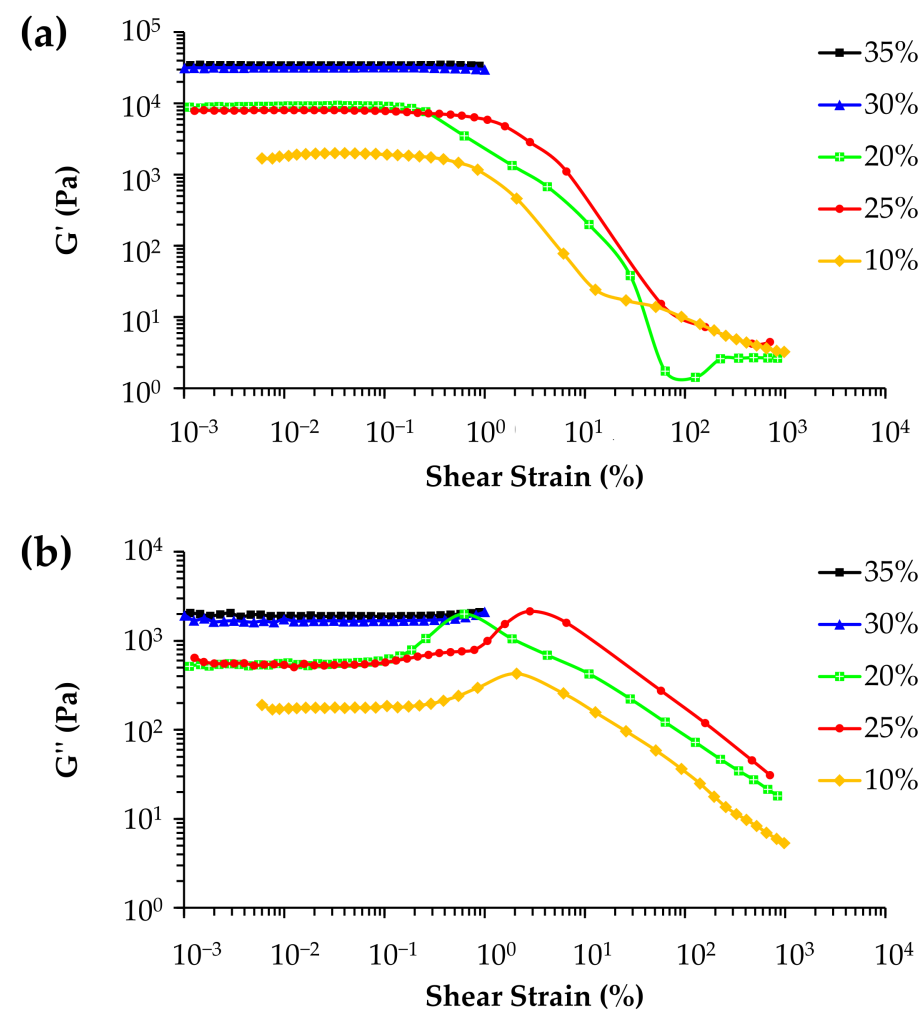

Figure 3. Shear strain dependence of the viscoelastic parameters: (a) elastic modulus, $\mathrm{G}^{\prime}$, and (b) storage modulus $\mathrm{G}^{\prime \prime}$ on solid concentration.

Moreover, the option for Pluronic F-127 hydrogels also brings some associated drawbacks, including an increased difficulty in preparing inks with high solids loadings. In the present case, the most concentrated ink (40 vol.\% solids) was difficult to prepare with a high homogeneity. The intrinsic porosity of the bioactive glass particles retaining some dispersing liquid is likely to account for this [33]. The rheological properties of inks based on Pluronic F-127 hydrogels being less sensitive to the overall solids volume fraction and other processing parameters make the processing conditions trickier to tune and more difficult, and some further refinements will be required in future studies.

\subsection{Printing}

The CAD models of scaffolds were built using RoboCAD software. A model consisting of a squared lattice with $10 \mathrm{~mm} \times 10 \mathrm{~mm} \times 4 \mathrm{~mm}$ dimensions with a meandering path inside it and each rod being spaced by a length equal to its diameter was designed, as seen in Figure 4. A small, solid rectangular piece was also freeform modelled for use in dilatometry tests, as seen in Figure 5. Based on this model, the porosity of the scaffold was estimated according to this CAD model. The mathematical model developed for deriving the porosity fraction is presented in the Appendix A.

The printing was carried out by loading the pastes into syringes with a couple nozzle of $410 \mu \mathrm{m}$ inner diameter. Air conditioning and a humidifier were used to keep the printing environment at approximately $25^{\circ} \mathrm{C}$ and $80 \%$ relative humidity. The step in the $\mathrm{Z}$ direction that takes place when the printer is switching to the next layer was initially set in the CAD model at $\Delta \mathrm{Z}=0.322 \mathrm{~mm}$. However, this degree of overlap was revealed to be excessive because the inks are not so stiff, as shown in Figure 3, and the deposited filaments would undergo some flowing while their internal structure is being recovered. Therefore, this parameter was changed from the default value of $0.322 \mathrm{~mm}$ to $0.410 \mathrm{~mm}$ in order to prevent the dragging of the previously deposited underlying layers and the geometrical deformation of the printing parts. This also means that the real overlap among the different deposited layers can exclusively be attributed to the incipient flowing undergone by the 
deposited filaments while their internal structure is being recovered. The benefits of this change in the set overlap degree from $\Delta \mathrm{Z}=0.322 \mathrm{~mm}$ to $\Delta \mathrm{Z}=0.410 \mathrm{~mm}$ in the model can be observed in Figure 4 . The parts on the left-hand side printed with $\Delta \mathrm{Z}=0.322 \mathrm{~mm}$ present high geometrical deformations in contrast with those on the right-hand side printed with $\Delta \mathrm{Z}=0.410 \mathrm{~mm}$. According to the CAD and mathematical models, these scaffolds have an internal porosity of $\sim 70 \%$. Although this value is specific to a green body, as long as the shrinkage is isotropic during sintering, the sintered scaffolds should also have the same internal porosity. In the current case, it is reasonable to presume isotropic shrinkage, at least within the amenable limits of the mechanical stresses that would otherwise develop during drying and sintering, leading to the bending and cracking of the scaffolds, putting their integrity in danger. Since bending and cracking were not observed, and isotropic shrinkage can be assumed. Thus, the porosity calculation for the green body should also hold for the sintered body.

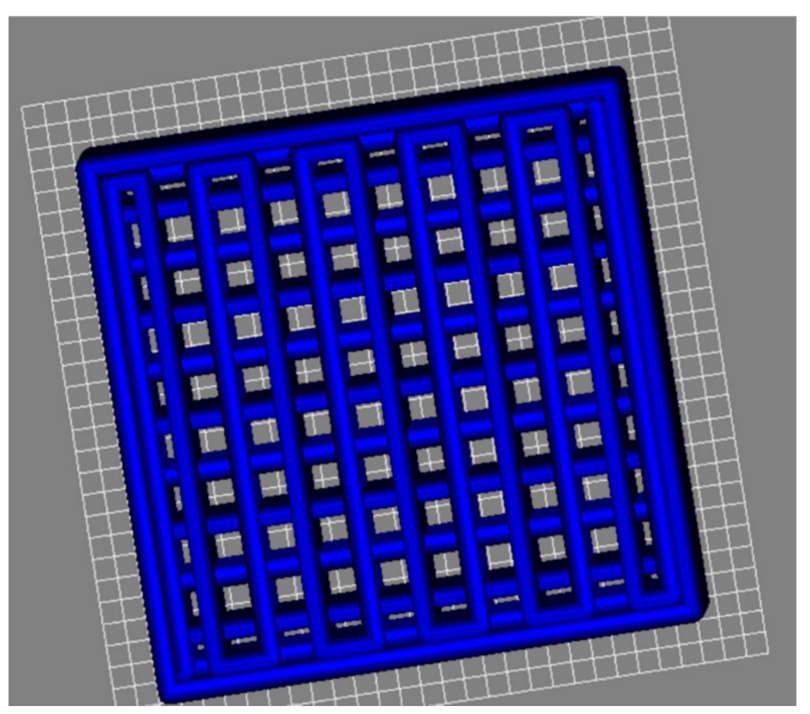

Figure 4. Planned scaffold structure designed according to the CAD model presented in Figure 1 of the article [26] using rods with $d=0.410 \mathrm{~mm}$, a center to center distance between successive filaments, $s=0.820 \mathrm{~mm}$, and an interlayer distance $h=0.527 \mathrm{~mm}$, corresponding to $\Delta \mathrm{Z}=0.322 \mathrm{~mm}$.
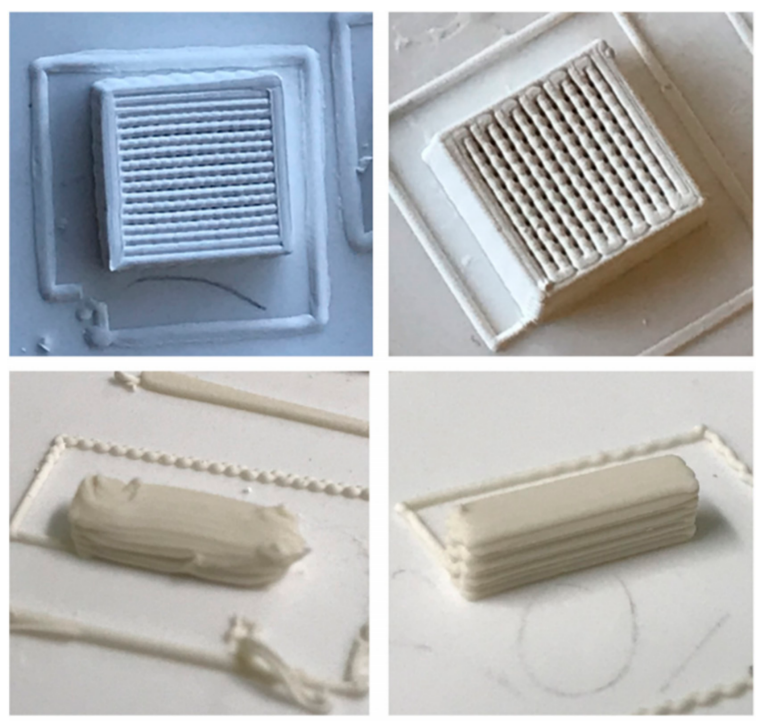

Figure 5. Effects of the overlap degrees set in the CAD model on geometrical definition of printed parts. 
It can be clearly seen that a significant improvement of geometrical definition was achieved for the bioglass scaffold and for the specimen for dilatometry measurements printed with $\Delta \mathrm{Z}=0.410 \mathrm{~mm}$, i.e., when a null overlap was set in the CAD model, allowing the real overlap to be dictated just by the incipient flowing of the newly deposited filament. Therefore, this seems to be an interesting expedient to help remediating the unsatisfactory stiffness of robocasting inks based on Pluronic F-127 hydrogels. However, refinements in the ink preparation process, such as gradually adding the powder in different steps intermediated with mixing steps at suitable high rotations and for longer time periods, could be explored in future studies aiming at homogeneous inks with higher solids loadings and degrees of stiffness.

\subsection{Thermal Treatments}

Scaffold debinding was first attempted at $300{ }^{\circ} \mathrm{C}$ for $2 \mathrm{~h}$, resulting in a grey tone scaffold, likely due to carbon residues from the incomplete burn-out of the Pluronic F-127. Therefore, to select the debinding and sintering parameters, a previously dried (at $100{ }^{\circ} \mathrm{C}$ ) and powdered paste was submitted to thermal analysis within the temperature range from 25 to $900{ }^{\circ} \mathrm{C}$, performed at a heating rate of $10^{\circ} \mathrm{C} \mathrm{min}-1$. The curves of the thermogravimetric analysis displayed in Figure 6 exhibit a broad thermal band ranging from 150 to $600{ }^{\circ} \mathrm{C}$ with DTG peaks at $\sim 200$ and $\sim 320^{\circ} \mathrm{C}$ and $\sim 400{ }^{\circ} \mathrm{C}$, which correspond to the faster degradation rates of the polymer in the TGA curve. The small weight loss up to $\sim 200{ }^{\circ} \mathrm{C}$ and peaking at this temperature is attributed to the desorption of water [34]. The onset of polymer thermal decomposition occurs at about $\sim 320^{\circ} \mathrm{C}$, as shown in the TDA curve relative to the pure Pluronic F-127 sample. This thermal behaviour agrees with the observations made by other authors $[34,35]$. The peak at $700{ }^{\circ} \mathrm{C}$ is likely due to the burn-out of residual carbon. The analysis suggests that a complete burn-out of the Pluronic F-127 is likely to occur at $400{ }^{\circ} \mathrm{C}$ under slow heating, in accordance with the literature [36]. Heating the printed scaffolds at a rate of $0.5^{\circ} \mathrm{C} \mathrm{min}^{-1}$ up to $400{ }^{\circ} \mathrm{C}$ and plateauing for $4 \mathrm{~h}$ produced light-coloured scaffolds, indicating an apparent complete burn-off.

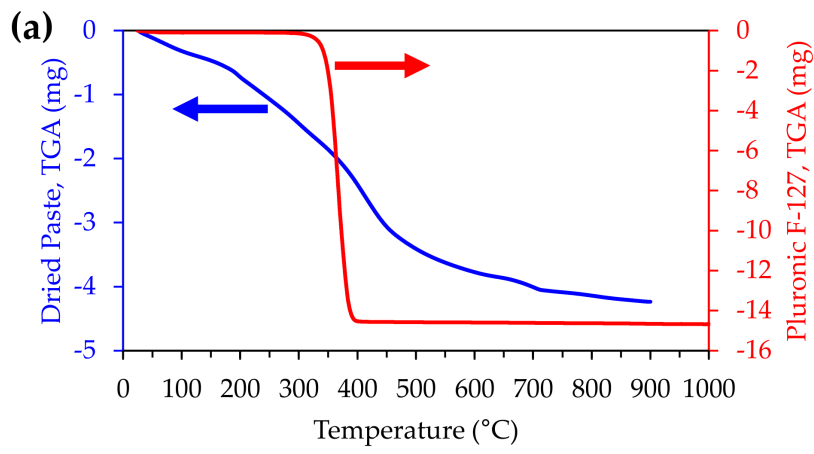

(b)

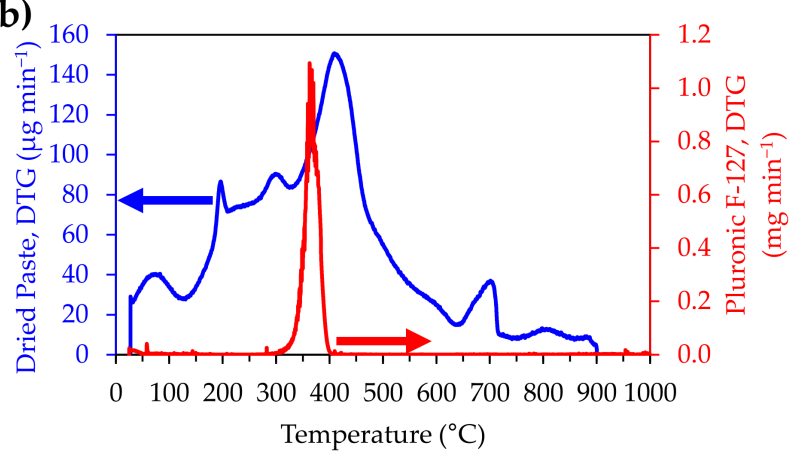

Figure 6. Comparative thermogravimetric analysis of pure Pluronic F-127 and of dried bioactive glass printing paste: (a) TGA, (b) DTG. 
Before sintering, a dilatometric test was carried out using a rectangular specimen with $\sim 10.8 \mathrm{~mm}$ of length (shown in Figure 5). The specimen was previously debinded at $400{ }^{\circ} \mathrm{C}$ so it could be placed into the dilatometric analyser without fracture. The dilatometry curve displayed in Figure 7 shows that slow dimensional changes only started to occur at about $450{ }^{\circ} \mathrm{C}$ and gradually accelerated up to $760{ }^{\circ} \mathrm{C}$, followed by an accentuated shrinkage up to $850{ }^{\circ} \mathrm{C}$, and reached the minimal dimensions at approximately $900^{\circ} \mathrm{C}$. Moreover, the preliminary dimensional assessments of the printed scaffolds before and after sintering revealed that anisotropic shrinkage was not an issue here. Therefore, the sintered scaffolds also have the same internal porosity as the green body, $70 \%$.

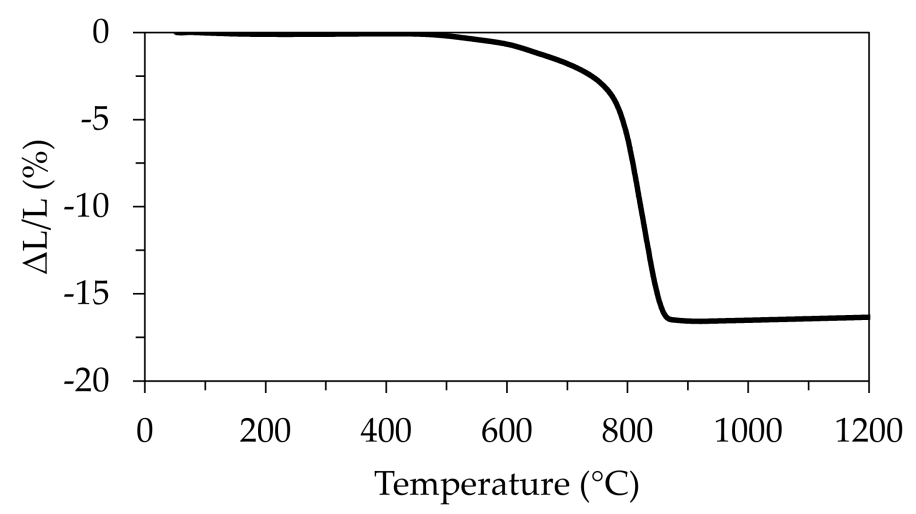

Figure 7. Dilatometric behaviour of the green sample printed from the paste containing 35 vol.\% bioactive glass.

\subsection{Preliminary Mechanical Properties Assessment through Compressive Strength Tests}

Compressive strength tests were performed on five representative scaffolds. According to the followed ISO 17162 (2014), the specimens must have a height larger than the width and length values, which is not the case. However, the main purpose of these tests was evaluating the reproducibility of the mechanical properties and to infer if they could be suitable for the intended applications in bone regeneration and tissue engineering. The bioglass scaffolds sintered at 600 and $700{ }^{\circ} \mathrm{C}$ were fragile and likely to break when handled, so they were not selected for the compressive tests. Their poor mechanical strength can be attributed to the insufficient densification degrees of the struts, as deduced from Figure 7. The values for the scaffolds sintered at $800{ }^{\circ} \mathrm{C}$ are present in Table 3 . It can be seen that the average compressive strength $(8.39 \pm 0.98 \mathrm{MPa})$ is well within the range reported for human cancellous (trabecular) bone (2-12 MPa) $[37,38]$.

Table 3. Dimensions and compressive strength data for bioactive glass scaffolds sintered at $800{ }^{\circ} \mathrm{C}$.

\begin{tabular}{cccccc}
\hline Sample No. & $\mathbf{x}$ & $\begin{array}{c}\text { Dimensions } \mathbf{( m m )} \\
\mathbf{y}\end{array}$ & $\mathbf{z}$ & Force (N) & $\begin{array}{c}\text { Compressive } \\
\text { Strength (MPa) }\end{array}$ \\
\hline 1 & 9.64 & 804 & 3.43 & 804 & 8.48 \\
2 & 9.66 & 944 & 3.41 & 944 & 9.96 \\
3 & 9.60 & 657 & 3.48 & 657 & 7.14 \\
4 & 9.78 & 846 & 3.34 & 846 & 8.76 \\
5 & 9.64 & 716 & 3.42 & 716 & 7.62 \\
\hline \multicolumn{5}{c}{ Average Compressive Strength (MPa): } \\
\hline
\end{tabular}

\subsection{Biocompatibility Assays}

To assess the biocompatibility of the different scaffolds and their suitability for biological application, MG-63 cells were exposed to culture medium extract where the scaffolds were incubated for $24 \mathrm{~h}$. Viability values for the four different samples can be seen in Figure 8 . For all the scaffolds, the cell viability values are above the $70 \%$ threshold, which, according to ISO 10993-5:2009(E) (2009), suggests they are safe and thus suitable for biomed- 
ical applications. In the cells exposed to $100 \%$ extract, the cell viability varies from $80.9 \%$ in samples sintered at $600{ }^{\circ} \mathrm{C}$ to $90.5 \%$ in samples sintered at $900{ }^{\circ} \mathrm{C}$. Surprisingly, the samples sintered at $900{ }^{\circ} \mathrm{C}$ had the best results compared to those that were sintered at $600{ }^{\circ} \mathrm{C}$, displaying the lowest cell viability. However, the scaffolds sintered at $700{ }^{\circ} \mathrm{C}$ had slightly higher cell viability values than those sintered at $800^{\circ} \mathrm{C}$. Therefore, a trend cannot be established between sintering temperature and cell viability. Moreover, the observed changes in the trend are lower than the error bars, which further makes the trend uncertain. These data highlight the need for a thorough characterization of the sintered scaffolds in future studies.

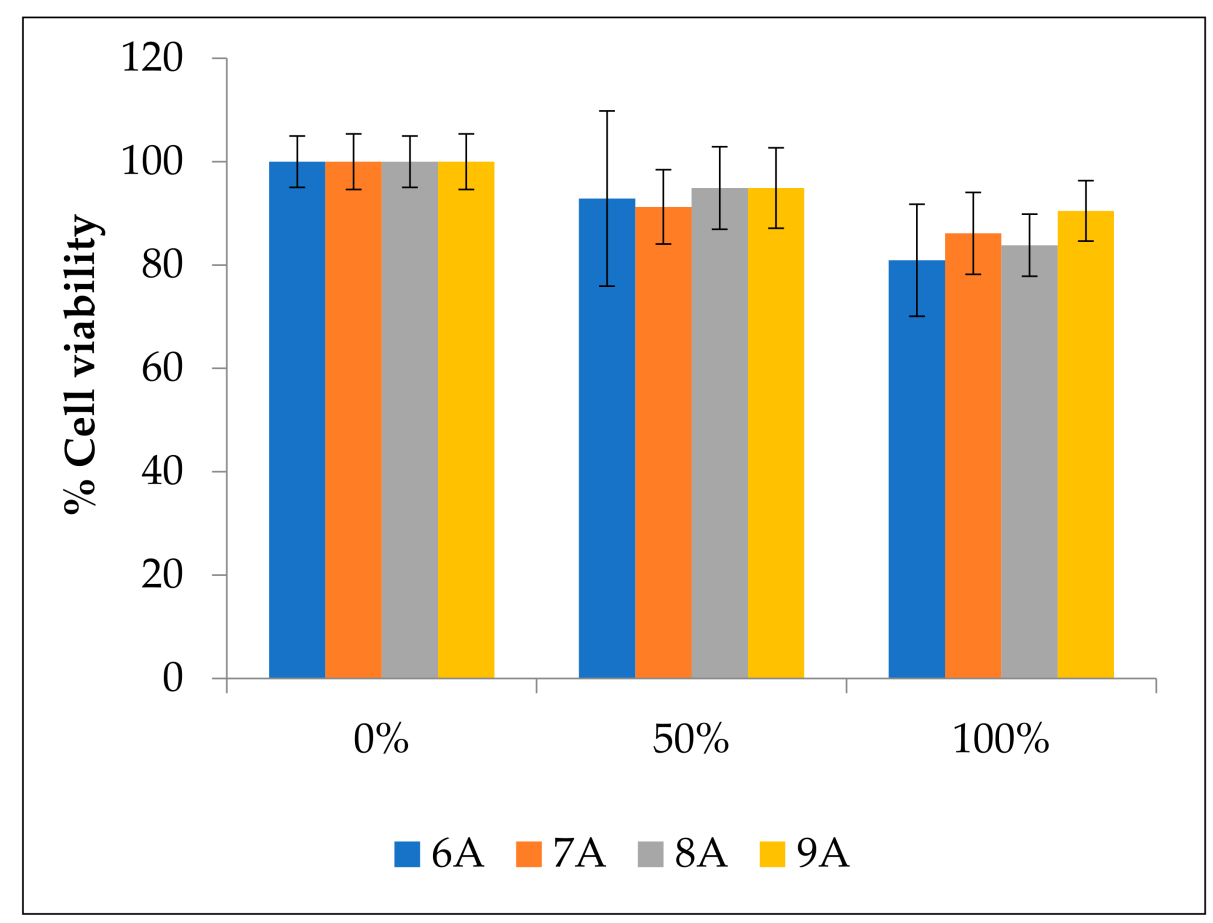

Figure 8. Cell viability values for scaffolds sintered at $600(6 \mathrm{~A}), 700(7 \mathrm{~A}), 800(8 \mathrm{~A})$, and $900^{\circ} \mathrm{C}$ (900A) at different extract concentrations: $\%$ ( $0 \%$ extract, 100\% DMEM medium), 50\% (50\% extract, $50 \%$ DMEM medium), $100 \%$ (100\% extract, $0 \%$ DMEM medium).

\section{Conclusions}

Porous bioactive glass scaffolds with macro pore size, macro pore volume fraction, and mechanical properties suitable for bone ingrowth in bone regeneration and tissue engineering applications were successfully fabricated by robocasting. The amorphous sol-gel derived bioactive glass powder with the composition of $\mathrm{SiO}_{2}-\mathrm{CaO}-\mathrm{MgO}-\mathrm{P}_{2} \mathrm{O}_{5}$ was calcined at $600{ }^{\circ} \mathrm{C}$, milled down to a mean particle size of $4.63 \pm 3.58 \mu \mathrm{m}$, and dispersed in a $33 \mathrm{wt} . \%$ concentrated Pluronic F-127 hydrogel to form printing inks with various solids loadings. The assessment of the rheological properties of the inks revealed the following salient features: (i) the inks tend to exhibit shear-thinning behaviours that are required for $3 \mathrm{D}$ printing; (ii) the high viscosity of the background Pluronic F-127 hydrogel limits the quantity of solids that can be dispersed, hindering the achievement of homogeneous inks with high solid volume fractions and degrees of stiffness; (iii) the maximum solids loading for the printable inks was limited to $35 \mathrm{vol.} \%$; (iv) the elastic modulus of the ink containing $35 \mathrm{vol} . \%$ of the bioactive glass powder was at least one order of magnitude lower than the values usually required for granting good shape retention capability to the extruded filaments. Therefore, the depositing filaments still undergo some incipient flowing while their internal structure is being recovered, allowing a sufficient overlap with the previously printed layer. This overlap degree, together with that imposed by the CAD model, was revealed to be excessive and could lead to printed parts with geometrical deformations. This problem could be overcome by setting the overlap degree in the CAD model at zero. 
The debinding of the printed parts needs to be conducted under low heating rates to properly degrade the polymeric chains while keeping the integrity of the scaffolds. A sintering temperature of at least $800{ }^{\circ} \mathrm{C}$ is necessary for conferring suitable compressive strength values to the porous scaffolds, matching those of human cancellous (trabecular) bones. The ability of the material to form a hydroxyapatite layer after only 7 days of SBF treatment was an attractive feature already revealed in the previous study. The biological assessment revealed cell viability values over the $70 \%$ threshold and up to $~ 90 \%$, which strongly supports that these bioactive glass scaffolds are safe and suitable for biomedical applications, bone regeneration, and tissue engineering.

Author Contributions: Conceptualization, J.M.F.F., R.B. and H.O; methodology, R.B. and P.O.; software, R.B. and A.G.; validation, J.M.F.F., A.G. and H.O.; formal analysis, R.B., A.G. and P.O.; investigation, R.B. and P.O.; resources, J.M.F.F. and H.O.; data curation, J.M.F.F., A.G. and H.O.; writingoriginal draft preparation, R.B.; writing-review and editing, J.M.F.F., A.G. and H.O.; visualization, A.G. and H.O.; supervision, J.M.F.F. and H.O.; project administration, J.M.F.F.; funding acquisition, J.M.F.F. and H.O. All authors have read and agreed to the submitted version of the manuscript.

Funding: This research received no external funding.

Data Availability Statement: Data is contained within the article. Supplementary data to this study are available in [doi:10.3390/ma14164515].

Acknowledgments: This work was developed within the scope of the projects CICECO-Aveiro Institute of Materials, FCT Ref. UID/CTM/50011/2019 and CESAM - Centre for Environmental and Marine Studies (UIDB/50017/2020 \& UIDP/50017/2020) financed by national funds through the Portuguese Foundation for Science and Technology (FCT/MCTES). FCT is also acknowledged for the research contract under Scientific Employment Stimulus to H.O. (CEECIND/04050/2017). P.O. acknowledges the University of Aveiro for the PhD grant (BD/REIT/8623/2020). AG is grateful for the support from the São Paulo Research Foundation (FAPESP Processo $n^{\circ}$ 2021/06370-0) and CeRTEV (Center for Research, Technology, and Education in Vitreous Materials-process FAPESP ${ }^{\circ}$ 2013/07793-6).

Conflicts of Interest: The authors declare no conflict of interest.

\section{Appendix A}

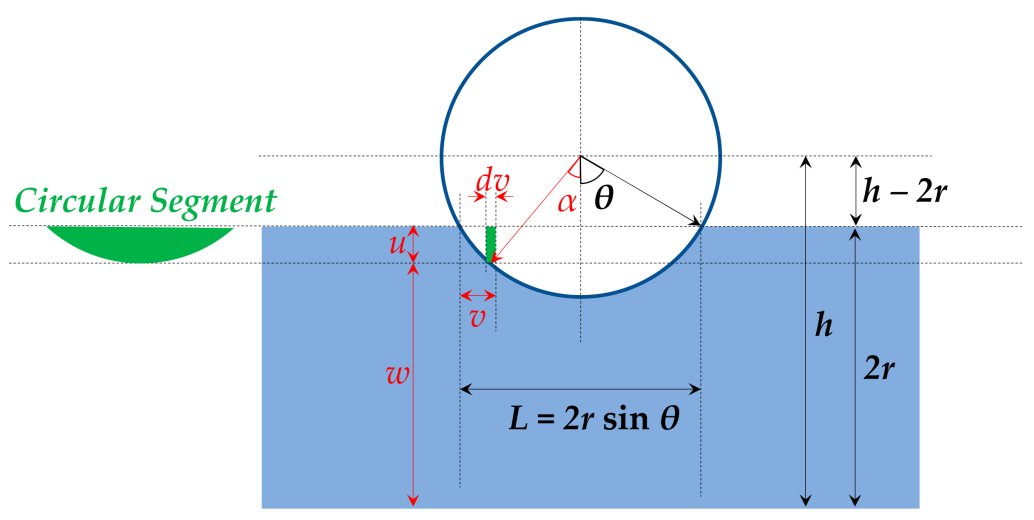

Figure A1. Schematics of a rod cross section and its overlap with a beneath and perpendicularly deposited filament. The parameters in black are fixed, while those in red are variable.

The derivation of the analytical solution for the porosity of the scaffold model used in the current work involves subtracting each overlap volume of the rods. To find a single overlap volume $\left(V_{o}\right)$, we must integrate over the angular variable $\alpha$, from $-\theta$ to $\theta$, according to the figure above. From the figure, where all the variables are identified in red, the following geometric relationships can be established.

$$
\theta=\cos ^{-1}\left(\frac{h-2 r}{r}\right)
$$




$$
\begin{aligned}
& u=r \cos \alpha+2 r-h \\
& v=r(\sin \theta+\sin \alpha)
\end{aligned}
$$

The differential change in $v$ is:

$$
d v=r \cos \alpha d \alpha
$$

For a given value of $u$, the cross-section of the overlapped volume forms a circular segment (shown in green) whose area $\left(A_{0}\right)$ is given by:

$$
A_{o}(u)=r^{2} \cos ^{-1}\left(\frac{r-u}{r}\right)-(r-u) \sqrt{r^{2}-(r-u)^{2}}
$$

Therefore, a single overlap volume is given by:

$$
V_{o}=\int_{v=0}^{L} A_{o} d v
$$

Substituting the equation for $A_{o}$, and changing the variables from $u$ and $v$ to $\alpha$, we get:

$$
\begin{gathered}
V_{o}=\int_{\alpha=-\theta}^{\theta}\left[r^{2} \cos ^{-1}\left(\frac{r-r \cos \alpha+h-2 r}{r}\right)-(r-r \cos \alpha+h-2 r) \sqrt{r^{2}-(r-r \cos \alpha+h-2 r)^{2}}\right] r \cos \alpha d \alpha \\
V_{o}=r^{3} \int_{\alpha=-\theta}^{\theta}\left[\cos ^{-1}\left(\frac{h}{r}-1-\cos \alpha\right)-\left(\frac{h}{r}-1-\cos \alpha\right) \sqrt{1-\left(\frac{h}{r}-1-\cos \alpha\right)^{2}}\right] \cos \alpha d \alpha
\end{gathered}
$$

The authors are not aware if the above integral has an analytical solution; therefore, it was solved numerically.
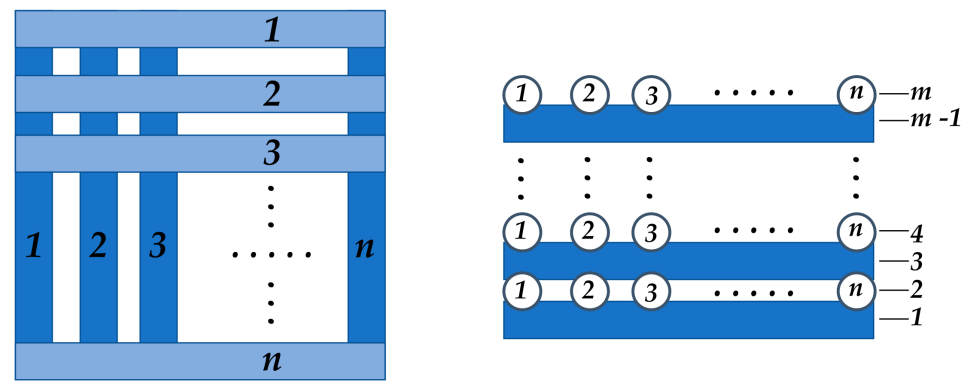

Figure A2. Schematic view of a $n \times n \times m$ grid of rods.

If we consider two layers of $n$ number of rods, they will form a $n \times n$ square grid with $n^{2}$ number of overlaps. The area occupied by the grid is $n^{2} s^{2}$. For $m+1$ number of layers, the height of the scaffold would be $m h$, with a total number of $m n^{2}$ overlapped volumes. The overall volume of the cuboid formed by the $n \times n \times m$ grid of rods is given by:

$$
V_{T}=m n^{2} s^{2} h
$$

The volume of each rod is $n \pi r^{2} s$. There are a total of $m n$ number of rods. Therefore, the total volume of all the rods is $V_{R}$.

$$
V_{R}=m n^{2} \pi r^{2} s
$$

The solid volume $(V)$ of the scaffold is the volume of all the rods with the overlapped volume subtracted. Therefore, it is given by: 


$$
V=V_{R}-m n^{2} V_{o}=m n^{2}\left(\pi r^{2} s-V_{o}\right)
$$

The porosity is now given by:

$$
p=1-\frac{V}{V_{T}}=1-\frac{m n^{2}\left(\pi r^{2} s-V_{o}\right)}{m n^{2} s^{2} h}=1-\frac{\pi r^{2}}{s h}+\frac{V_{o}}{s^{2} h}
$$

For a relatively small overlap of the rods, the overlap volume could be negligible; therefore, the porosity could be approximated as:

$$
p \approx 1-\frac{\pi r^{2}}{s h}
$$

The parameters $s, h$, and $r$ used in the printing were 820,527, and $205 \mu \mathrm{m}$, respectively. Accordingly, a single overlap volume $V_{o}$ is $4.45 \times 10^{-3}(\mathrm{~mm})^{3}$. Therefore, a macro-porosity of $\sim 70 \%$ was obtained under these conditions. Interestingly, this porosity fraction is in good agreement with the value calculated using another model [29] for a similar design of scaffolds.

\section{References}

1. Berman, B. 3-D printing: The new industrial revolution. Bus. Horiz. 2012, 55, 155-162. [CrossRef]

2. Kunovjanek, M.; Knofius, N.; Reiner, G. Additive manufacturing and supply chains-A systematic review. Prod. Plan. Control 2020, 1-21. [CrossRef]

3. Tofail, S.A.M.; Koumoulos, E.P.; Bandyopadhyay, A.; Bose, S.; O’Donoghue, L.; Charitidis, C. Additive manufacturing: Scientific and technological challenges, market uptake and opportunities. Mater. Today 2018, 21, 22-37. [CrossRef]

4. Watson, J.K.; Taminger, K.M.B. A decision-support model for selecting additive manufacturing versus subtractive manufacturing based on energy consumption. J. Clean. Prod. 2018, 176, 1316-1322. [CrossRef] [PubMed]

5. Newman, S.T.; Zhu, Z.; Dhokia, V.; Shokrani, A. Process planning for additive and subtractive manufacturing technologies. CIRP Ann. 2015, 64, 467-470. [CrossRef]

6. Karunakaran, K.P.; Suryakumar, S.; Pushpa, V.; Akula, S. Low cost integration of additive and subtractive processes for hybrid layered manufacturing. Robot. Comput. Integr. Manuf. 2010, 26, 490-499. [CrossRef]

7. Singamneni, S.; Yifan, L.V.; Hewitt, A.; Chalk, R.; Thomas, W.; Jordison, D. Additive Manufacturing for the Aircraft Industry: A Review. J. Aeronaut. Aerosp. Eng. 2019, 8, 214. [CrossRef]

8. Manogharan, G.; Wysk, R.A.; Harrysson, O.L.A. Additive manufacturing-integrated hybrid manufacturing and subtractive processes: Economic model and analysis. Int. J. Comput. Integr. Manuf. 2016, 29, 473-488. [CrossRef]

9. Cozmei, C.; Caloian, F. Additive Manufacturing Flickering at the Beginning of Existence. Procedia Econ. Financ. 2012, 3, 457-462. [CrossRef]

10. Feldmann, C.; Delke, V.; Wasserman, M.E. Strategically Aligning Additive Manufacturing Supply Chains for Sustainability and Effectiveness. IFAC-PapersOnLine 2019, 52, 260-264. [CrossRef]

11. Bonnin Roca, J.; Vaishnav, P.; Fuchs, E.R.H.; Morgan, M.G. Additive Manufacturing: Policy Needed. SSRN Electron. J. 2016. [CrossRef]

12. Feilden, E.; Blanca, E.G.-T.; Giuliani, F.; Saiz, E.; Vandeperre, L. Robocasting of structural ceramic parts with hydrogel inks. J. Eur. Ceram. Soc. 2016, 36, 2525-2533. [CrossRef]

13. Cesarano, J. A Review of Robocasting Technology. MRS Proc. 1998, 542, 133. [CrossRef]

14. Cesarano, J., III; King, B.H.; Denham, H.B. Recent Developments in Robocasting of Ceramics and Multimaterial Deposition. In Proceedings of the International Solid Freeform Fabrication Symposium, Austin, TX, USA, 11-13 August 1998; pp. 697-703.

15. Brazete, D.; Neto, A.S.; Ferreira, J.M.F. Optimization of zirconia inks to fabricate 3D porous scaffolds by robocasting. Clin. Technol. 2019, 49, 5-10.

16. Smay, J.E.; Cesarano, J.; Lewis, J.A. Colloidal Inks for Directed Assembly of 3-D Periodic Structures. Langmuir 2002, 18, 5429-5437. [CrossRef]

17. Tuttle, B.A.; Smay, J.E.; Cesarano, J.; Voigt, J.A.; Scofield, T.W.; Olson, W.R.; Lewis, J.A. Robocast $\mathrm{Pb}\left(\mathrm{Zr}_{0.95} \mathrm{Ti}_{0.05}\right) \mathrm{O}_{3}$ Ceramic Monoliths and Composites. J. Am. Ceram. Soc. 2001, 84, 872-874. [CrossRef]

18. Li, Q.; Lewis, J.A. Nanoparticle Inks for Directed Assembly of Three-Dimensional Periodic Structures. Adv. Mater. 2003, 15, 1639-1643. [CrossRef]

19. Lewis, J.A.; Smay, J.E.; Stuecker, J.; Cesarano, J. Direct Ink Writing of Three-Dimensional Ceramic Structures. J. Am. Ceram. Soc. 2006, 89, 3599-3609. [CrossRef]

20. Nan, B.; Galindo-Rosales, F.J; Ferreira, J.M.F. 3D printing vertically: Direct ink writing free-standing pillar arrays. Mater. Today 2020, 35, 16-24. [CrossRef] 
21. Nan, B.; Gołębiewski, P.; Buczyński, R.; Galindo-Rosales, F.J.; Ferreira, J.M.F. Direct Ink Writing Glass: A Preliminary Step for Optical Application. Materials 2020, 13, 1636. [CrossRef]

22. Munch, E.; Franco, J.; Deville, S.; Hunger, P.; Saiz, E.; Tomsia, A.P. Porous ceramic scaffolds with complex architectures. JOM 2008, 60, 54-58. [CrossRef]

23. Ben-Arfa, B.A.E.; Palamá, I.E.; Miranda Salvado, I.M.; Ferreira, J.M.F.; Pullar, R.C. Cytotoxicity and bioactivity assessments for $\mathrm{Cu}^{2+}$ and $\mathrm{La}^{3+}$ doped high-silica sol-gel derived bioglasses: The complex interplay between additive ions revealed. J. Biomed. Mater. Res. Part A 2019, 107, 2680-2693. [CrossRef] [PubMed]

24. Ben-Arfa, B.A.E.; Miranda Salvado, I.M.; Ferreira, J.M.F.; Pullar, R.C. A hundred times faster: Novel, rapid sol-gel synthesis of bio-glass nanopowders (Si-Na-Ca-P system, Ca:P = 1.67) without aging. Int. J. Appl. Glas. Sci. 2017, 8, 337-343. [CrossRef]

25. Bento, R.; Gaddam, A.; Ferreira, J.M.F. Sol-gel synthesis and characterization of a quaternary bioglass for bone regeneration and tissue engineering. Materials 2021, 14, 4515. [CrossRef]

26. Ben-Arfa, B.A.E.; Miranda Salvado, I.M.; Pullar, R.C.; Ferreira, J.M.F. The influence of processing parameters on morphology and granulometry of a wet-milled sol-gel glass powder. Ceram. Int. 2018, 44, 12754-12762. [CrossRef]

27. Ben-Arfa, B.A.E.; Miranda Salvado, I.M.; Frade, J.R.; Pullar, R.C. Guidelines to adjust particle size distributions by wet comminution of a bioactive glass determined by Taguchi and multivariate analysis. Ceram. Int. 2019, 45, 3857-3863. [CrossRef]

28. Mosmann, T. Rapid colorimetric assay for cellular growth and survival: Application to proliferation and cytotoxicity assays. $J$. Immunol. Methods 1983, 65, 55-63. [CrossRef]

29. Gaddam, A.; Brazete, D.S.; Neto, A.S.; Nan, B.; Ferreira, J.M.F. Three-dimensional printing of zirconia scaffolds for load bearing applications: Study of the optimal fabrication conditions. J. Am. Ceram. Soc. 2021, 104, 4368-4380. [CrossRef]

30. Eqtesadi, S.; Motealleh, A.; Miranda, P.; Lemos, A.; Rebelo, A.; Ferreira, J.M.F. A simple recipe for direct writing complex $45 S 5$ Bioglass ${ }^{\circledR}$ 3D scaffolds. Mater. Lett. 2013, 93, 68-71. [CrossRef]

31. Eqtesadi, S.; Motealleh, A.; Miranda, P.; Pajares, A.; Lemos, A.; Ferreira, J.M.F. Robocasting of 45 S5 bioactive glass scaffolds for bone tissue engineering. J. Eur. Ceram. Soc. 2014, 34, 107-118. [CrossRef]

32. Nan, B.; Olhero, S.; Pinho, R.; Vilarinho, P.M.; Button, T.W.; Ferreira, J.M.F. Direct ink writing of macroporous lead-free piezoelectric $\mathrm{Ba}_{0.85} \mathrm{Ca}_{0.15} \mathrm{Zr}_{0.1} \mathrm{Ti}_{0.9} \mathrm{O}_{3}$. J. Am. Ceram. Soc. 2019, 102, 3191-3203. [CrossRef]

33. Ben-Arfa, B.A.E.; Neto, A.S.; Miranda Salvado, I.M.; Pullar, R.C.; Ferreira, J.M.F. Robocasting: Prediction of ink printability in solgel bioactive glass. J. Am. Ceram. Soc. 2019, 102, 1608-1618. [CrossRef]

34. Kao, H.-M.; Chen, C.-L.; Chiao, S.-W. Solid Polymer Electrolyte Based on Pluronic P123 Triblock Copolymer-Siloxane OrganicInorganic Hybrid. J. Chin. Chem. Soc. 2005, 52, 693-699. [CrossRef]

35. Park, J.; Yu, M.K.; Jeong, Y.Y.; Kim, J.W.; Lee, K.; Phan, V.N.; Jon, S. Antibiofouling amphiphilic polymer-coated superparamagnetic iron oxide nanoparticles: Synthesis, characterization, and use in cancer imaging in vivo. J. Mater. Chem. 2009, 19, 6412. [CrossRef]

36. Dou, Q.; Abdul Karim, A.; Loh, X. Modification of Thermal and Mechanical Properties of PEG-PPG-PEG Copolymer (F127) with MA-POSS. Polymers 2016, 8, 341. [CrossRef] [PubMed]

37. Carter, D.R.; Schwab, G.H.; Spengler, D.M. Tensile Fracture of Cancellous Bone. Acta Orthop. Scand. 1980, 51, 733-741. [CrossRef] [PubMed]

38. Ben-Arfa, B.A.E.; Neto, S.; Miranda Salvado, I.M.; Pullar, R.C.; Ferreira, J.M.F. Robocasting of $\mathrm{Cu}^{2+} \& \mathrm{La}^{3+}$ doped sol-gel glass scaffolds with greatly enhanced mechanical properties: Compressive strength up to 14 MPa. Acta Biomater. 2019, 87, 265-272. [CrossRef] [PubMed] 